\title{
Effects of an overnight high-carbohydrate meal on muscle glycogen after rapid weight loss in male collegiate wrestlers
}

\author{
Emi Kondo ${ }^{1 *}$ (D) Keisuke Shiose ${ }^{2}$, Takuya Osawa² ${ }^{2}$ Keiko Motonaga ${ }^{2}$, Akiko Kamei ${ }^{1}$, Kohei Nakajima', \\ Hiroyuki Sagayama ${ }^{3}$,Takahiro Wada ${ }^{4}$, Shigeki Nishiguchi ${ }^{5}$ and Hideyuki Takahashi ${ }^{2,3}$
}

\begin{abstract}
Background: Severe rapid weight loss (RWL) induces a decrease in muscle glycogen (mGly). Nevertheless, adequate carbohydrate intake after RWL has not been reported to optimize muscle glycogen following a weigh-in the evening until a wrestling tournament morning. The purpose of this study was to investigate the effect of an overnight highcarbohydrate recovery meal of $7.1 \mathrm{~g} \mathrm{~kg}^{-1}$ following RWL on mGly concentration.

Methods: Ten male elite wrestlers lost 6\% of their body mass within $53 \mathrm{~h}$ and then subsequently ate three meals, within $5 \mathrm{~h}$, containing total of $7.1 \mathrm{~g} \mathrm{~kg}^{-1}$ of carbohydrates. mGly was measured by ${ }^{13} \mathrm{C}$-magnetic resonance spectroscopy before (BL) and after RWL (R0) at $2 \mathrm{~h}(\mathrm{R} 2)$, $4 \mathrm{~h}(\mathrm{R} 4)$, and $13 \mathrm{~h}$ (R13) after initiating the meal. Body composition, muscle cross-sectional area, and blood and urine samples were collected at BL, R0, and R13.

Results: Body mass decreased by $4.6 \pm 0.6 \mathrm{~kg}(p<0.05)$ and did not recover to BL levels in $\mathrm{R} 13(-1.7 \pm 0.6 \mathrm{~kg}$, $p<0.05)$. Likewise, $\mathrm{mGly}$ by $36.5 \% \pm 10.0 \%(p<0.05)$ and then did not reach BL levels by R13 $(p<0.05)$.

Conclusion: A high-carbohydrate meal of $7.1 \mathrm{~g} \mathrm{~kg}^{-1}$ after $6 \%$ RWL was not sufficient to recover mGly during a $13 \mathrm{~h}$ recovery phase. Participating in high-intensity wrestling matches with an mGly concentration below normal levels is maybe undesirable.
\end{abstract}

Keywords: Wrestling, Weight management, Recovery, Rapid weight loss, Rapid weight gain, Carbohydrate

\section{Background}

As wrestling is a weight-categorised sport, wrestlers and coaches take advantage of body size and physical strength using rapid weight loss (RWL) strategies. Until 2017, a rule of United World Wrestling stated that an official weigh-in had to be conducted on the evening before each competition [1]. In 2018, this rule changed to requiring a weigh-in each morning [2]. In contrast, Judo changed the weigh-in timing from morning before each match to the evening before the match [3]. Other sports, such as

\footnotetext{
*Correspondence: kondo.emi.fp@u.tsukuba.ac.jp

1 Sports Medical Center, Japan Institute of Sports Science, 3-15-1 Nishigaoka, Kita-ku, Tokyo 115-0056, Japan
}

Full list of author information is available at the end of the article professional boxing and mixed martial arts, still perform a weigh-in the day before the competition. Thus, there are some rules depend on the type of sports, and optimal weigh-in rules are still under argument.

Traditionally, many male wrestlers (38-69\%), particularly in the lightweight and middleweight classes, attempt to "make weight" by losing $>5 \%$ of their body mass approximately one week before their competition and then ingest fluids and food to recover their physical condition as quickly as possible [4-6]. Common RWL methods include food and fluid restriction, fasting, eating less food during each meal, decreasing carbohydrate intake, increasing exercise, saunas and baths, and training with rubber suits $[4,5,7]$. These methods original author(s) and the source, provide a link to the Creative Commons licence, and indicate if changes were made. The images or other third party material in this article are included in the article's Creative Commons licence, unless indicated otherwise in a credit line to the material. If material is not included in the article's Creative Commons licence and your intended use is not permitted by statutory regulation or exceeds the permitted use, you will need to obtain permission directly from the copyright holder. To view a copy of this licence, visit http://creativecommons.org/licenses/by/4.0/. The Creative Commons Public Domain Dedication waiver (http://creativeco mmons.org/publicdomain/zero/1.0/) applies to the data made available in this article, unless otherwise stated in a credit line to the data. 
induce dehydration $[8,9]$, and decrease muscle glycogen (mGly) $[10,11]$. As a result, aerobic and anaerobic performance decrease [12] and immune [13, 14] and cognitive functions are impaired [15]. However, wrestlers and coaches have considered that even if RWL reduces strength or endurance performance, these can be recovered through sufficient fluid and nutrition intake because the weigh-in was conducted in the evening before the day of each tournament. In addition, a recent review reported that an RWL of $5-8 \%$ body mass with a small impact on health and performance has remained acceptable practice [16]. Thus, if we accept RLW within a suitable range, the best nutrition strategies for recovery must be elucidated to achieve the best performance.

MGly is a major energy source of moderate- to highintensity exercise [17]. Wrestling is an intermittent, combative sport requiring technical, tactical and psychological skill that demands absolute muscle strength and power on both the upper and lower body $[18,19]$. Each match lasts approximately 6 min (two, 3 min rounds with a $30 \mathrm{~s}$ rest) including tackling, pushout, lifting, throwing, and blocking, which are high-intensity movements [20], and wrestlers must compete in up to five matches [21]. Therefore, the strategies of mGly recovery in the morning before the wrestling matches are important.

To the best of our knowledge, few studies, with only one manipulated carbohydrate intake after RWL, have investigated nutrient strategies to recover mGly overnight, which is generally the time between weigh-in and the first match. Only one study of Rankin et al. [22] reported the effects of carbohydrate intake from a highcarbohydrate meal (75\% energy) compared with those of a moderate-carbohydrate meal (47\% energy) for a $5 \mathrm{~h}$ recovery period on anaerobic performance. In the study, anaerobic performance tended to be higher after a high-carbohydrate meal than a moderate-carbohydrate meal, which was $99.1 \%$ and $91.5 \%$ of baseline after recovery, respectively, although mGly concentration was not obtained. As a nutrition guideline, the carbohydrate recommendation after or during exercise is described to be dependent on the exercise situation, such as intensity and duration [23]. However, the carbohydrates required to recover mGly between RWL and the match on the next morning remain to be elucidated.

The aim of this study was to examine the effect of a high-carbohydrate meal of $7.1 \mathrm{~g} \mathrm{~kg}^{-1}$ on the mGly concentration after RWL and an overnight recovery meal. To obtain the recovery process of mGly and short-term mGly synthesis, we measured these at 2 and $4 \mathrm{~h}$ after initiating the recovery meal. We hypothesized that a highcarbohydrate meal induces recovery of the mGly deficit after an overnight recovery phase.

\section{Methods}

\section{Participants}

Ten male collegiate wrestlers (age, $20.9 \pm 0.5$ year; height, $168.9 \pm 4.3 \mathrm{~cm}$; body mass, $73.2 \pm 8.2 \mathrm{~kg} ; \%$ body fat, $11.2 \% \pm 2.0 \%$ ) were recruited from two teams in Japanese colleage after receiving information about this study from their team coaches. All subjects belonged to the East Japan Collegiate League and had competed in wrestling matches on an international $(n=3)$, national level $(\mathrm{n}=5)$ and regional level $(\mathrm{n}=2)$. Eligibility into the study required participants: (1) $\geq 18$ years of age, (2) had experienced losing over $6 \%$ of their body mass before a major competition, (3) free of any metabolic, thyroid, or heart diseases. All participants submitted their written informed consent before the experiment began. This study was approved by the Institutional Review Board of the Japan Institute of Sports Sciences (036 in 2014).

\section{Experimental design}

All participants were instructed to complete their daily life dietary and training records before the experiment. Participants visited our institute on the day before baseline (BL) measurements and ate their usual amount of dinner in a buffet restaurant by 21:00. They were given instructions to abstained from taking alcohol or stimulant beverages and to refrain from hard exercise for at least $12 \mathrm{~h}$ prior to $\mathrm{BL}$ measurement. They were allowed to drink mineral water after 23:00.

We obtained anthropometric measurements, body composition, and mGly concentration, and took blood and urine samples at 06:30 (BL). After the measurements, we instructed them to lose $6 \%$ of their body mass. The methods of weight loss is described in detail elsewhere [8]. At $53 \mathrm{~h}$ after BL measurements, they visited the laboratory for measurements after 6\% RWL (R0). After the R0 measurements had been collected, the participants were provided with three prescribed meals (Table 1) to consume between 17:30 and 23:00, which was similar to previous study [24]. MGly concentrations were obtained $2 \mathrm{~h}$ (R2) and $4 \mathrm{~h}$ (R4) after initiating the prescribed meal. Measurements were taken again on the next morning at 06:30, $13 \mathrm{~h}$ after initiating the prescribed meal (R13).

\section{Anthropometric data and body composition}

All participants voided their bladders before measurements of height, body mass, and body composition were taken, and they each wore a bathing suit. Height and body mass were obtained barefoot to the nearest $0.1 \mathrm{~cm}$ with an automatic stadiometer and weight scale (A \& D Co. Ltd, Tokyo, Japan) after voiding. Body composition was obtained using dual X-ray absorptiometry (DXA; QDR 4500, Discovery A [S/N 84498], fan-beam scanner, software version 12.7.3.2; Hologic, Waltham, MA, USA). 
Table 1 Time, menu, and nutritional intake of prescribed recovery meal

\begin{tabular}{|c|c|c|c|c|c|}
\hline \multirow{2}{*}{$\begin{array}{l}\text { Period } \\
\text { Time (hh:mm) }\end{array}$} & & \multirow{2}{*}{$\begin{array}{l}\text { R0-R2 } \\
\text { 17:30-19:00 }\end{array}$} & \multirow{2}{*}{$\begin{array}{l}\text { R2-R4 } \\
\text { 21:00-22:00 }\end{array}$} & \multirow{2}{*}{$\begin{array}{l}\text { R4-R13 } \\
\text { 22:30-23:00 }\end{array}$} & \multirow[t]{2}{*}{ Total } \\
\hline & & & & & \\
\hline Menu & & $\begin{array}{l}\text { Sports drink, Sports jully A bowl of } \\
\text { rice topped with chicken and eggs, } \\
\text { Hamburg, Miso soup with pork and } \\
\text { vegetables, Baumkuchen, Water }\end{array}$ & $\begin{array}{l}\text { Wheat noodle with seasoning soy sauce, } \\
\text { A bowl of rice topped with chicken and } \\
\text { eggs, } 100 \% \text { pure orange juice, Baum- } \\
\text { kuchen, Water }\end{array}$ & Baumkuchen, Water & \\
\hline \multicolumn{6}{|c|}{ Nutrient contents } \\
\hline \multirow[t]{2}{*}{ Energy } & (kcal) & $1633 \pm 210$ & $1014 \pm 164$ & $231 \pm 83$ & $2879 \pm 310$ \\
\hline & $\left(\mathrm{kcal} \mathrm{kg}^{-1}\right)$ & $22.3 \pm 0.8$ & $13.8 \pm 1.5$ & $3.2 \pm 1.5$ & $39.3 \pm 1.0$ \\
\hline \multirow[t]{2}{*}{ Carbohydrate } & (g) & $290 \pm 46$ & $199 \pm 23$ & $33 \pm 20$ & $522 \pm 47$ \\
\hline & $\left(\mathrm{g} \mathrm{kg}^{-1}\right)$ & $3.9 \pm 0.2$ & $2.7 \pm 0.4$ & $0.5 \pm 0.3$ & $7.1 \pm 0.2$ \\
\hline \multirow[t]{2}{*}{ Protein } & (g) & $37 \pm 5$ & $23 \pm 5$ & $3 \pm 1$ & $64 \pm 9$ \\
\hline & $\left(\mathrm{g} \mathrm{kg}^{-1}\right)$ & $0.5 \pm 0.0$ & $0.3 \pm 0.0$ & $0.0 \pm 0.0$ & $0.9 \pm 0.0$ \\
\hline Fat & (g) & $36 \pm 1$ & $14 \pm 9$ & $10 \pm 0$ & $60 \pm 10$ \\
\hline Sodium & (mg) & $2826 \pm 216$ & $1192 \pm 429$ & $58 \pm 9$ & $4076 \pm 589$ \\
\hline Food weight & (g) & $2414 \pm 431$ & $1353 \pm 334$ & $917 \pm 379$ & $4685 \pm 514$ \\
\hline \multicolumn{6}{|c|}{ Percentage of energy } \\
\hline Carbohydrate & $(\%)$ & $70.8 \pm 2.4$ & $79.2 \pm 7.3$ & $54.5 \pm 7.6$ & $72.6 \pm 1.4$ \\
\hline Protein & $(\%)$ & $9.2 \pm 0.4$ & $9.1 \pm 1.1$ & $5.6 \pm 0.1$ & $8.8 \pm 0.3$ \\
\hline Fat & $(\%)$ & $20.0 \pm 2.3$ & $11.7 \pm 6.7$ & $39.8 \pm 7.5$ & $18.5 \pm 1.1$ \\
\hline
\end{tabular}

Nutrient contents are described as mean \pm SD $(n=10)$

Detail method of DXA is described in the previous study [8].

\section{Cross-sectional area measurements}

The cross-sectional area (CSA) of the right femoral region was obtained with the participants in a supine position by 3-Tesla magnetic resonance imaging (MRI) device (Magnetom Skyra; Siemens, Erlangen, Germany) at each time point. First, localization images were obtained from the 3 anatomic planes (sagittal, coronal, transverse). The CSA of the muscles and subcutaneous fat in the femoral region was estimated at $50 \%$ position between the upper end of the greater trochanter and the knee joint gap (repetition time $500 \mathrm{~ms}$, echo time $8.2 \mathrm{~ms}$, matrix $256 \times 256$, field of view $240 \mathrm{~mm}$, thickness $10 \mathrm{~mm}$ ). Each CSA was computed by tracing each area using special image analysis software (ISIS, Hitachi Ltd., Japan) by one researcher.

\section{Muscle glycogen concentration}

MGly concentration from right thigh was measured using carbon $\left({ }^{13} \mathrm{C}\right)$-magnetic resonance spectroscopy (MRS), as described elsewhere $[25,26]$. To obtaine the ${ }^{13} \mathrm{C}$-glycogen signal, a 3-Tesla magnetic resonance system (Magnetom Verio; Siemens, Erlangen, Germany) with a ${ }^{13} \mathrm{C}-{ }^{1} \mathrm{H}$ double-tuned surface coil of $10 \mathrm{~cm}$ diameter (Takashima seisakusho, Japan) was used. The reproducibilityof mGly by ${ }^{13} \mathrm{C}$-MRS with repositioning and reshimming was coefficient of variation of $3.5 \%$ in our laboratory [25], and that of $6.6-9.5 \%$ in a previous study [27].

\section{Blood and urine sampling and analysis}

Blood samples were collected from the antecubital vein into vacuum-sealed serum collection tubes and vacuum tubes containing dipotassium ethylene-diamine tetraacetic acid (EDTA) and sodium fluoride at three collection time points (BL, R0, and R13). The samples were centrifuged at $3000 \mathrm{rpm}$ for $10 \mathrm{~min}$ at $4{ }^{\circ} \mathrm{C}$, and whole blood, serum and plasma samples were stored at $2-4{ }^{\circ} \mathrm{C}$, except plasma for arginine vasopressin, which was stored at $-80{ }^{\circ} \mathrm{C}$ until analysis. Urine samples for urinary specific gravity and osmotic pressure were obtained from each participant into $10 \mathrm{~mL}$ tubes and stored at $2-4{ }^{\circ} \mathrm{C}$ until analysis. All blood and urine analyses were outsourced to an independent laboratory (LSI Medience Corporation, Tokyo, Japan).

\section{Energy and macronutrient intake}

A survey of all food and fluid intake was conducted before the baseline measurement (baseline) and during the $53 \mathrm{~h}$ RWL period (weight-loss period). We instructed participants to weigh all consumed food, supplements, and bevarages using a scale, and record these with photograph. Energy and macronutrient intake determined over the 3 days included 2 training days and 1 day off before the baseline measurement, and daily intake was calculated by adjusting for the training period as 6 days. Participants recorded all consumed food and fluid during the $53 \mathrm{~h} \mathrm{RWL}$ period. The 
methods of calculation of energy and macronutrient intake is described in detail elsewhere [8].

\section{Statistical analysis}

Sample size was calculated from the statistical power $(1-\beta)$ at 0.8 , the $\alpha$ error at 0.05 and significant minimum effect size (f) at 0.6 based on the change in mGly concentration [11]. This power calculation determined that a minimum sample size of eight participants (for a repeated one-way ANOVA with five measurements) was required to detect a statistically significant difference in mGly concentration change using G*Power 3.1. Statistical analyses were performed using IBM SPSS statistics 24 for Windows (IBM, Chicago IL, USA) and expressed as means \pm standard deviation. Paired t-test was used to compare mean difference between baseline and weight-loss period. Comparisons of means were performed using linear mixed model, and multiple comparison test was performed using Bonferroni posthoc test.

\section{Results}

\section{Nutrient intake and body mass}

Daily energy intake decreased by $67.6 \% \pm 11.2 \%$ during the weight-loss period compared with that of the baseline (Table 2). Body mass significantly decreased by $4.6 \pm 0.6 \mathrm{~kg}(6.4 \% \pm 0.7 \%)$ at R0 compared with BL ( $p<0.05$; 95\% confidence interval, CI 4.2-5.2) (Fig. 1). Body mass then increased by $2.2 \pm 0.5 \mathrm{~kg}$ after the first recovery meal (R0-R2) and by $3.3 \pm 0.5 \mathrm{~kg}$ after the second (R2-R4), but body mass at R13 was $1.7 \pm 0.6 \mathrm{~kg}$ $(2.3 \% \pm 0.8 \%)$ lower than BL.

Table 2 Daily nutritional intake

\begin{tabular}{llcc}
\hline Component & & Baseline & Weight-loss period \\
\hline Energy & $(\mathrm{kcal})$ & $3426 \pm 774$ & $1123 \pm 492$ \\
Carbohydrate & $(\mathrm{g})$ & $491 \pm 138$ & $156 \pm 68$ \\
& $\left(\mathrm{~g} \mathrm{~kg}^{-1}\right)$ & $6.7 \pm 1.8$ & $2.1 \pm 0.9$ \\
Protein & $(\mathrm{g})$ & $122 \pm 28$ & $42 \pm 20$ \\
& $\left(\mathrm{~g} \mathrm{~kg}^{-1}\right)$ & $1.7 \pm 0.3$ & $0.6 \pm 0.2$ \\
Fat & $(\mathrm{g})$ & $108 \pm 22$ & $37 \pm 20$ \\
Sodium & $(\mathrm{mg})$ & $5181 \pm 1307$ & $1928 \pm 632$ \\
Food weight & $(\mathrm{g})$ & $3673 \pm 1512$ & $1501 \pm 654$ \\
Percentage of energy & & \\
Protein & $(\%)$ & $14.3 \pm 0.8$ & $15.1 \pm 2.9$ \\
Fat & $(\%)$ & $29.2 \pm 4.7$ & $29.3 \pm 8.5$ \\
Carbohydrate & $(\%)$ & $56.5 \pm 4.9$ & $55.6 \pm 10.6$
\end{tabular}

Values are expressed as mean $\pm S D(n=10)$

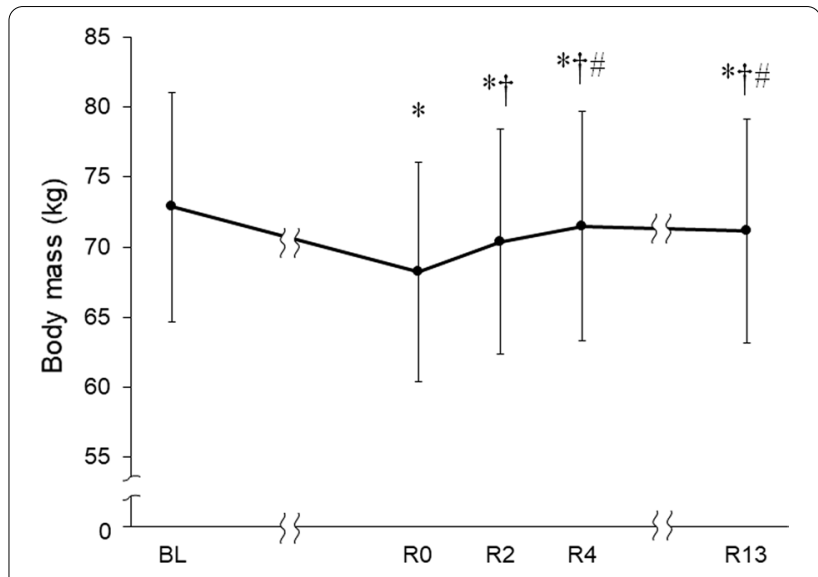

Fig. 1 Change in body mass between rapid weight loss and recovery. Wrestlers underwent rapid weight loss ( $6 \%$ body mass reduction). Body mass was measured before (BL) and after rapid weight loss (R0) at $2 \mathrm{~h}$ (R2), $4 \mathrm{~h}$ (R4), and $13 \mathrm{~h}$ (R13) after initiating meal. Data are presented as means and $S D(n=10) .{ }^{*} p<0.05$ versus $\mathrm{BL}{ }^{\dagger} p<0.05$ versus $\mathrm{RO} ;{ }^{\#} p<0.05$ versus $\mathrm{R} 2$

\section{Body composition and cross-sectional area of the right thigh}

A mean fat mass reduction of $0.4 \pm 0.3 \mathrm{~kg} \quad(p<0.05$; 95\% CI $0.1-0.8)$ and fat-free soft tissue reduction of $4.2 \pm 0.3 \mathrm{~kg}(p<0.05 ; 95 \%$ CI 3.8-4.6) were observed after RWL (R0) (Table 3). At R13, fat mass did not change from R0; however, the fat-free soft tissue recovered by $3.0 \pm 0.4 \mathrm{~kg}(p<0.05 ; 95 \%$ CI 2.6-3.4). Muscle CSA significantly decreased by $5.9 \% \pm 1.3 \%(p<0.05 ; 95 \%$ CI 9.4-12.2) from $\mathrm{BL}$ to $\mathrm{R} 0$ and increased by $3.8 \% \pm 2.0 \%$

Table 3 Body composition and cross-sectional area of right thigh

\section{$\begin{array}{lll}\text { BL } & \text { R0 } & \text { R13 }\end{array}$}

Body composition

Fat-free soft tissue mass (kg)

Bone mineral mass $(\mathrm{kg})$ $\begin{array}{rrr}8.0 \pm 1.8^{*} & 8.0 \pm 1.9^{*} \\ 63.2 \pm 7.0 & 59.0 \pm 6.7^{*} & 62.0 \pm 6.6^{* \dagger}\end{array}$ $3.2 \pm 0.3 \quad 3.2 \pm 0.3 \quad 3.2 \pm 0.3^{*}$

Cross-sectional area

Muscle cross-sectional area $\quad 180.8 \pm 18.9 \quad 170.3 \pm 19.3^{*} \quad 177.0 \pm 18.0^{* \dagger}$ $\left(\mathrm{cm}^{2}\right)$

$\begin{array}{llll}\text { Subcutaneous fat }\left(\mathrm{cm}^{2}\right) & 32.7 \pm 10.6 & 31.2 \pm 10.0 & 31.7 \pm 10.0\end{array}$

$\begin{array}{llll}\text { Bone }\left(\mathrm{cm}^{2}\right) & 6.5 \pm 0.7 & 6.4 \pm 0.7 & 6.5 \pm 0.7\end{array}$

$\begin{array}{lllr}\text { Residual }\left(\mathrm{cm}^{2}\right) & 3.8 \pm 0.7 & 3.9 \pm 0.6 & 3.7 \pm 0.5\end{array}$

Total cross-sectional area $\quad 223.7 \pm 21.9 \quad 211.8 \pm 22.0^{*} \quad 218.8 \pm 20.9^{* \dagger}$ $\left(\mathrm{cm}^{2}\right)$

Circumference $(\mathrm{cm}) \quad 48.4 \pm 2.4 \quad 47.2 \pm 2.6^{*} \quad 47.9 \pm 2.3^{* \dagger}$

Values are expressed as mean $\pm S D(n=10) . B L$ baseline. ${ }^{*} p<0.05$ versus $B L$; ${ }^{\dagger} p<0.05$ versus $R 0$

Fat-free soft tissues mass excluded fat and bone mineral mass 
from R0 to R13 ( $p<0.05,95 \%$ CI 3.5-9.8), which was still lower than that of the BL $(p<0.05 ; 95 \%$ CI 1.8-6.4). There were no significant difference in the cross-sectional area of subcutaneous fat, bone and residual did not change at any point in time.

\section{Muscle glycogen concentration}

MGly concentration decreased by $36.5 \% \pm 10.0 \%$ at R0 compared with $\mathrm{BL}(p<0.05$; 95\% CI 15.1-35.3) (Fig. 2), had not recovered by R2 $(p<0.05$; 95\% CI $14.5-30.7)$ or R4 ( $p<0.05$; 95\% CI 2.8-30.7) and remained lower than BL $(p<0.05$; 95\% CI 1.5-23.8), even 13 h (R13) after initiating the prescribed meal containing $7.1 \mathrm{~g} \mathrm{~kg}^{-1}$ of carbohydrate. MGly store rate was $1.8 \pm 2.7 \mathrm{mM} \mathrm{h}^{-1}$ from $\mathrm{R} 0$ to $\mathrm{R} 2,3.3 \pm 4.2 \mathrm{mM} \mathrm{h}^{-1}$ between $\mathrm{R} 2$ and $\mathrm{R} 4$ and $0.5 \mathrm{mM} \mathrm{h}^{-1}$ between $\mathrm{R} 4$ and R13.

\section{Blood and urine content}

Because one participant ate a dinner containing a higher fat content before pre-measurement compared with their usual meal, we analyzed the data from nine participants (Table 4). Hemoglobin, total protein, albumin, creatinine, uric acid, urea nitrogen, free fatty acid, total cholesterol, high-density lipoprotein (HDL)-cholesterol, low-density lipoprotein (LDL)-cholesterol, sodium, magnesium, and urinary specific gravity at R0 were greater than those at BL. By contrast, glucose, insulin, triglyceride, and testosterone were lower at R0 than at BL. Additionally, creatinine, uric acid, and triglyceride at R13 were statistically different compared with these measurements at BL.

\section{Discussion}

In the present study, we discovered that body mass and mGly concentrations do not return to pre-RWL levels after overnight recovery, even with the consumption of a high-carbohydrate meal ( $7.1 \mathrm{~g} \mathrm{~kg}^{-1}$ body mass) after $6 \%$ RWL. To our knowledge, this is the first study that obtained mGly changes during RWL and recovery using ${ }^{13} \mathrm{C}$-MRS. If we convert our mGly values to wet weight, assuming the density of fat-free mass is $1.1 \mathrm{~kg} \mathrm{~L}^{-1}$ [28], our basal values $\left(69.0 \pm 10.3 \mathrm{mmol} \mathrm{kg}^{-1}\right.$ wet wt) agree with those of Houston et al. [10] $\left(62 \mathrm{mmol} \mathrm{kg}^{-1}\right.$ wet wt in the vastus lateralis). The mGly concentration decreased by $36.5 \%$ after $6 \%$ RWL for $53 \mathrm{~h}$ in the current study. The reduction in mGly concentration was also similar to that of Houston's study ( $46 \%$ for a $96 \mathrm{~h}$ RWL of $8 \%$ ). The mGly reduction rate calculated from the percentage of reduction and duration of RWL was $17 \%$ per day in the current study, $11 \%$ per day in Houston's study. Thus, our results supported this previous study. Our participants' intake of carbohydrate and protein were drastically less than that of $\mathrm{BL}$ values or dietary recommendations for weight loss [29]. Therefore, the amount of decrease in mGly was reasonable.

The fat-free soft tissue and muscle CSA decreased by $6.3 \%$ and $5.8 \%$ after RWL and recovered by $4.5 \%$ and $3.7 \%$ after taking the prescribed meal in the current study. These changes were similar to the study by Kukidome et al. [30], who reported that a lower muscle area decreased by $5.9 \%$ after $7.0 \%$ weight loss for 1 -week and regained by $4.2 \%$ by the wrestling tournament.
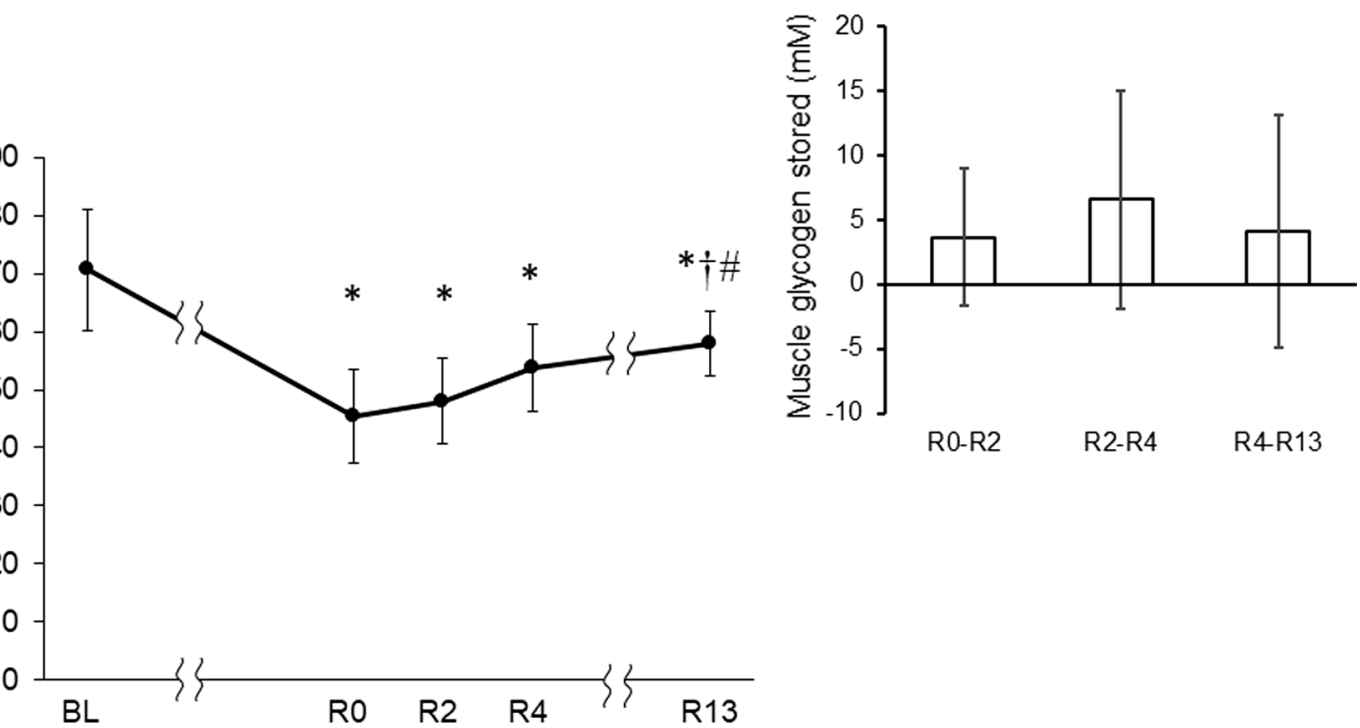

Fig. 2 Change in muscle glycogen between rapid weight loss and recovery. Muscle glycogen was measured before (BL) and after rapid weight loss (R0) at $2 \mathrm{~h}(\mathrm{R} 2), 4 \mathrm{~h}$ (R4), and $13 \mathrm{~h}$ (R13) after initiating meal. Data are presented as means and SD ( $\mathrm{n}=10)$. BL, baseline; ${ }^{*} p<0.05$ versus $\mathrm{BL} ;{ }^{\dagger} p<0.05$ versus $\mathrm{RO}$; $\#<0.05$ versus $R 2$ 
Table 4 Change in biomarkers

\begin{tabular}{|c|c|c|c|c|}
\hline Variable & BL & Ro & R13 & Reference ranges \\
\hline \multicolumn{5}{|l|}{ Blood } \\
\hline Hemoglobin $\left(\mathrm{g} \mathrm{dL}^{-1}\right)$ & $15.0 \pm 0.7$ & $15.6 \pm 0.9^{*}$ & $14.8 \pm 0.7^{\dagger}$ & $13.5-17.5$ \\
\hline Hematocrit (\%) & $45.0 \pm 1.9$ & $46.5 \pm 2.5$ & $44.6 \pm 1.7^{\dagger}$ & $39.7-52.4$ \\
\hline Total protein $\left(\mathrm{g} \mathrm{dL}^{-1}\right)$ & $7.3 \pm 0.3$ & $8.2 \pm 0.6^{*}$ & $7.2 \pm 0.4^{\dagger}$ & $6.7-8.3$ \\
\hline Albumin $\left(\mathrm{g} \mathrm{dL}^{-1}\right)$ & $4.6 \pm 0.1$ & $5.1 \pm 0.3^{*}$ & $4.5 \pm 0.1^{\dagger}$ & $3.8-5.3$ \\
\hline Creatinine $\left(\mathrm{mg} \mathrm{dL}^{-1}\right)$ & $0.87 \pm 0.11$ & $1.06 \pm 0.14$ & $0.94 \pm 0.11$ & $0.61-1.04$ \\
\hline Uric acid $\left(\mathrm{mg} \mathrm{dL}^{-1}\right)$ & $5.5 \pm 0.7$ & $7.8 \pm 1.1^{*}$ & $6.3 \pm 1.0^{* \dagger}$ & $3.8-7.0$ \\
\hline Urea nitrogen ( $\mathrm{mg} \mathrm{dL}^{-1}$ ) & $15.3 \pm 4.5$ & $22.5 \pm 4.0$ & $17.0 \pm 2.7$ & $8.0-20.0$ \\
\hline Glucose $\left(\mathrm{mg} \mathrm{dL}^{-1}\right)$ & $87 \pm 5$ & $81 \pm 7^{*}$ & $87 \pm 5^{\dagger}$ & 70-109 \\
\hline Insulin $\left(\mu \cup \mathrm{mL}^{-1}\right)$ & $4.4 \pm 1.9$ & $2.3 \pm 1.0$ & $3.6 \pm 1.3^{\dagger}$ & $1.7-10.4$ \\
\hline Triglyceride $\left(\mathrm{mg} \mathrm{dL}^{-1}\right)$ & $118 \pm 56$ & $44 \pm 12^{*}$ & $55 \pm 11^{*}$ & $30-149$ \\
\hline Free fatty acid (mEq $\left.\mathrm{L}^{-1}\right)$ & $0.25 \pm 0.05$ & $0.73 \pm 0.37^{*}$ & $0.35 \pm 0.10^{\dagger}$ & $0.10-0.90$ \\
\hline Total cholesterol $\left(\mathrm{mg} \mathrm{dL}^{-1}\right)$ & $179 \pm 27$ & $199 \pm 25^{*}$ & $175 \pm 20^{\dagger}$ & $120-219$ \\
\hline HDL-cholesterol $\left(\mathrm{mg} \mathrm{dL}^{-1}\right)$ & $60 \pm 8$ & $71 \pm 7^{*}$ & $62 \pm 7^{\dagger}$ & $40-85$ \\
\hline LDL-cholesterol $\left(\mathrm{mg} \mathrm{dL}^{-1}\right)$ & $97 \pm 24$ & $115 \pm 23^{*}$ & $98 \pm 17^{\dagger}$ & $65-139$ \\
\hline Sodium $\left(\mathrm{mEq} \mathrm{L}^{-1}\right)$ & $140 \pm 2$ & $142 \pm 1^{*}$ & $139 \pm 2^{\dagger}$ & $137-147$ \\
\hline Potassium (mEq L ${ }^{-1}$ ) & $4.7 \pm 0.3$ & $4.5 \pm 0.2$ & $4.7 \pm 0.3$ & $3.5-5.0$ \\
\hline Chlorine (mEq L ${ }^{-1}$ ) & $103 \pm 1$ & $104 \pm 2$ & $102 \pm 2^{\dagger}$ & $98-108$ \\
\hline Magnesium (mEq L ${ }^{-1}$ ) & $2.2 \pm 0.1$ & $2.5 \pm 0.2^{*}$ & $2.2 \pm 0.2^{\dagger}$ & $1.9-2.5$ \\
\hline Arginine vasopressin $\left(\mathrm{pg} \mathrm{mL}^{-1}\right)$ & $9.1 \pm 7.0$ & $16.1 \pm 8.2$ & $10.4 \pm 6.0$ & $\leq 4.2$ \\
\hline Testosterone $\left(\mathrm{ng} \mathrm{mL}^{-1}\right)$ & $6.68 \pm 1.45$ & $4.75 \pm 2.66^{*}$ & $6.27 \pm 1.04^{\dagger}$ & $1.92-8.84$ \\
\hline \multicolumn{5}{|l|}{ Urine } \\
\hline Urinary specific gravity & $1.025 \pm 0.010$ & $1.037 \pm 0.004^{*}$ & $1.026 \pm 0.010^{\dagger}$ & $1.006-1.030$ \\
\hline Osmotic pressure $\left(\mathrm{mOs} \mathrm{mL}^{-1}\right)$ & $886 \pm 297$ & $1166 \pm 140^{*}$ & $809 \pm 305^{\dagger}$ & $50-1300$ \\
\hline
\end{tabular}

Values are expressed as mean $\pm \mathrm{SD}(\mathrm{n}=9) .{ }^{*} p<0.05$ versus $\mathrm{BL}^{+}{ }^{\dagger} p<0.05$ versus $\mathrm{R} 0$

Our participants experienced dehydration such as fluid restriction and sweating with rubber suits during RWL, which affect total body water and the percentage of water in fat-free mass [8]. Indeed, several blood and urine indexes indicated dehydration (total protein, albumin, uric acid, sodium, magnesium and urinary specific gravity) at R0. Therefore, decrease in fat-free soft tissue and muscle CSA may be mainly associated with a decrease in hydration status in fat-free soft tissue. However, increase in the muscle CSA likely reflects rehydration in fat-free soft tissue and increase in intracellular water by glycogen accumulation. Most of blood and urine indexes of R13 returned to BL in the current study. In addition, previous studies suggested that mGly loading increases in muscle CSA of the vastus muscles and was probably due to an increase in intracellular water binding to glycogen granule $[26,31]$. Furthermore, we found that total body water changed after RWL and recovery in the previous study [8], indicating that these body water changes might relate to mGly change.

RLW-induced reduction in mGly concentration did not again reach $\mathrm{BL}$ values after $13 \mathrm{~h}$ recovery in the current study. Most studies have examined short-term
$(0-6 \mathrm{~h})$ or long-term $(>24 \mathrm{~h})$ recovery strategies, and few studies examined a $12 \mathrm{~h}$ mGly recovery. Piehl et al. [32] reported that mGly recovered to $68.8 \%$ of at-rest values at $10 \mathrm{~h}$ after exhaustion (18\% of mGly at rest), and it took $46 \mathrm{~h}$ to recover to rest levels. The calculated means of carbohydrate intake in their study were $216 \mathrm{~g}$ $\left(5.1 \mathrm{~g} \mathrm{~kg}^{-1}\right)$ for a $10 \mathrm{~h}$ recovery and $1116 \mathrm{~g}\left(15.9 \mathrm{~g} \mathrm{~kg}^{-1}\right)$ for a $46 \mathrm{~h}$ recovery. Although the mGly restoration in current study (81.7\%) was higher than the previous study [32], if athletes could consume more carbohydrates for longer periods, such as in professional boxing or mixed martial arts (e.g., $24 \mathrm{~h}$ ), mGly recovery would likely have been enhanced. The mGly storage rate was $1.8 \mathrm{mM} \mathrm{h}^{-1}$ from R0 to R2, $3.3 \mathrm{mM} \mathrm{h}^{-1}$ from R2 to R4, and $0.5 \mathrm{mM} \mathrm{h}^{-1}$ from R4 to R13 (mean, $1.1 \mathrm{mM} \mathrm{h}^{-1}$ for a $13 \mathrm{~h}$ recovery). MGly accumulation calculated from Houton's study [10] was $1.6 \mathrm{mmol} \mathrm{kg}$ wet $\mathrm{wt}^{-1} \mathrm{~h}^{-1}$ for a $3 \mathrm{~h}$ recovery, which is similar to the current study. However, these values are lower than the mGly accumulation range of 5-10 mmol kg wet $\mathrm{wt}^{-1} \mathrm{~h}^{-1}$ after extreme endurance exercise [33]. Therefore, it was considered that the recovery of mGly may be lower after RWL than after endurance exercise. 
We considered several reasons for the low mGly storage in the current study. First, glucose transporter isoform (GLUT-4) relates closely to glucose uptake. During and after endurance exercises, muscle contraction increases insulin-independent glucose uptake to muscle by GLUT-4 translocation. However, in the present study, we expected translocated GLUT-4 to be less than that after exhaustive exercise because the participants did not eat the recovery meal immediately after exercising. GLUT-4 mediated glucose uptake is strongly affected by insulin, that effect is larger than insulin-independent glucose uptake [34]. Participants in the current study were wrestlers who were well trained and ingested large amounts of carbohydrates after RWL. Hence, we believe that the difference in insulin-independent glucose uptake after exercise is rarely relevant. Second, mGly reduction after RWL was lower (36.5\%) than that of previous studies (67-91\%) [32, 35]. Zachwieja et al. [36] reported that mGly and glycogen synthase activities were negatively correlated [36]. Indeed, in our study, mGly concentration at R0 was $45.4 \mathrm{mM}$, which was higher than that in previous post-exercise studies [35, 37]. Third, the amount of carbohydrate intake may affect mGly restoration. Although a recent review recommended $7-10 \mathrm{~g} \mathrm{~kg}^{-1}$ of carbohydrates during an overnight recovery period after RWL [16], $7.1 \mathrm{~g} \mathrm{~kg}^{-1}$ of carbohydrate may be insufficient to restore mGly. In the current study, serum insulin levels were decreased by RWL and recovered by consuming a high-carbohydrate meal. Furthermore, free fatty acid levels increased at R0 and returned at R13. These data suggest that RWL induced gluconeogenesis, and we expect that not only mGly but also liver glycogen was decreased. Therefore, more carbohydrates may be needed to fill glycogen in both the liver and muscle. Finally, we considered that the macronutrient balance affects mGly storage after RWL. Previously, Burke et al. [38] provided evidence that when the carbohydrate intake is $<1.2 \mathrm{~g} \mathrm{~kg}^{-1} \mathrm{~h}^{-1}$, the addition of protein enhances post-exercise mGly synthesis. By contrast, the fat content ( $60 \mathrm{~g}, 18.5 \%$ energy) in the current study may prevent carbohydrate absorption. Eating high glycemic index carbohydrate foods after prolonged exercise induces a greater recovery of mGly concentrations than low glycemic index carbohydrate foods [39]. Therefore, future studies should attempt to compare the meal-contained manipulated macronutrient.

This study has some limitations. First, as we did not measure physical performance, the relationship between high-carbohydrate intake after RWL and physical performance was equivocal. Second, we did not clarify the mechanism of mGly synthesis because interrupted blood samples and muscle samples could not be obtained during the recovery phase. Furthermore, since we only measured mGly in the right thigh, changes in mGly in other parts, such as arms or liver, were not clarified. Third, we did not have a control group, and we performed only one carbohydrate intervention. Therefore, further study is required to examine whether the amount of carbohydrate after RWL is associated with mGly recovery. Finally, we had estimated appropriate sample size by repeated oneway ANOVA before the experiment. Post-hoc test by the linear mixed model was justified enough power at 1.7 using Rstudio.

\section{Conclusions}

We conclude that a high-carbohydrate meal of $7.1 \mathrm{~g} \mathrm{~kg}^{-1}$ body mass after $6 \%$ RWL was insufficient to recover the mGly during a $13 \mathrm{~h}$ recovery phase. Therefore, to avoid wrestling match with lower mGly level, optimal nutritional recovery strategies need to be further investigated.

\section{Abbreviations \\ ANOVA: Analysis of variance; CSA: Cross-sectional area; DXA: Dual X-ray absorptiometry; EDTA: Ethylene-diamine tetraacetic acid; GLUT: Glucose trans- porter; HDL: High-density lipoprotein; LDL: Low-density lipoprotein; mGly: Muscle glycogen; MRI: Magnetic resonance imaging; RWL: Rapid weight loss.}

\section{Acknowledgements}

We would like to thank the volunteers who participated in this study. This study was supported by research grant from the Japan Institute of Sports Sciences.

\section{Authors' contributions}

EK, KS, TO, and HT analysed data. EK, KS, TO, HS, and HT interpreted results of experiments. EK, KS, TO, and HT prepared figures. EK, and HT drafted manuscript. EK, KS, HS, and HT edited and revised manuscript. EK, KS, TO, HS, KM, AK, KN, TW, SN, and HT approved final version of manuscript. EK, KS,TO, KM, AK, KN, TW, SN, and HT conception and design of research. EK, KS, TO, HS, KM, AK, $\mathrm{KN}$, and $\mathrm{HT}$ performed experiments. All authors have read and approved the manuscript.

\section{Funding}

This study was supported by research grant from the Japan Institute of Sports Science. The funding body had no role in the design of the study and collection, analysis, and interpretation of data or in writing the manuscript.

\section{Declarations}

Ethics approval and consent to participate

All procedures performed in this study involving human participants were in accordance with the ethical standards of the institutional research committee and with the 1964 Helsinki Declaration and its later amendments or comparable ethical standards. This study was approved by the Institutional Review Board of the Japan Institute of Sports Sciences (No. 036 in 2014). Written informed consent was obtained from all individual participants included in the study.

\section{Consent for publication}

All participants were informed about the experimental nature of the study and gave their written informed consent for the publication of relevant data.

\section{Competing interests}

The authors declare that are no competing interests regarding the study.

\section{Author details}

${ }^{1}$ Sports Medical Center, Japan Institute of Sports Science, 3-15-1 Nishigaoka, Kita-ku, Tokyo 115-0056, Japan. ${ }^{2}$ Department of Sports Research, Japan 
Institute of Sports Science, 3-15-1 Nishigaoka, Kita-ku, Tokyo 115-0056, Japan. ${ }^{3}$ Faculty of Health and Sport Sciences, University of Tsukuba, 1-1-1 Tennodai, Tsukuba, Ibaraki 305-8577, Japan. ${ }^{4}$ Faculty of Physical Education, Kokushikan University, 7-3-1 Nagayama, Tama-shi, Tokyo 206-8515, Japan. ${ }^{5}$ Faculty of International Studies, Takushoku University, 815-1 Tatemachi, Hachioji-shi, Tokyo 193-0985, Japan

Received: 3 January 2021 Accepted: 12 August 2021

Published online: 20 August 2021

\section{References}

1. United World Wrestling. International Wrestling Rules Switzerland: United World Wrestling; 2017. https://unitedworldwrestling.org/sites/default/ files/media/document/wrestling_rules_9.pdf. Accessed 22 July 2020.

2. United World Wrestling. International Wrestling Rules Switzerland: United World Wrestling; 2018. https://unitedworldwrestling.org/sites/default/ files/media/document/wrestling_rules_a_0.pdf. Accessed 29 Apr 2020.

3. International Judo Federation. Sports and Organization Rules of the International Judo Federation. 2013, editor2013. https://isaschools.org. uk/wp-content/uploads/2015/01/Judo-Rules.pdf. Accessed 2 Jan 2021.

4. Nishimaki M, Kondo E, Teo C, Nakajima K, Yamashita D. Prevalence, methods of rapid weight loss amongst elite Japanese wrestlers: a questionnaire-based study of the 2016 Japanese Wrestling Championship. J High Perform Sport. 2020;6:11-27.

5. Kordi R, Ziaee V, Rostami M, Wallace WA. Patterns of weight loss and supplement consumption of male wrestlers in Tehran. Sports Med ArthrosC Rehabil Ther Technol. 2011;3:4.

6. Irfan Y. Associations among dehydration, testosterone and stress hormones in terms of body weight loss before competition. Am J Med Sci. 2015;350:103-8.

7. Reale R, Slater G, Burke LM. Weight management practices of Australian olympic combat sport athletes. Int J Sports Physiol Perform. 2018;13:459-66.

8. Kondo E, Sagayama H, Yamada Y, Shiose K, Osawa T, Motonaga K, et al. Energy deficit required for rapid weight loss in elite collegiate wrestlers. Nutrients. 2018;10:536.

9. Pettersson S, Berg CM. Hydration status in elite wrestlers, judokas, boxers, and taekwondo athletes on competition day. Int J Sport Nutr Exerc Metab. 2014;24:267-75.

10. Houston ME, Marrin DA, Green HJ, Thomson JA. The effect of rapid weight loss on physiological functions in wrestlers. Phys Sportsmed. 1981;9:73-8.

11. Tarnopolsky MA, Cipriano N, Woodcroft C, Pulkkinen WJ, Robinson DC, Henderson JM, et al. Effects of rapid weight loss and wrestling on muscle glycogen concentration. Clin J Sport Med. 1996;6:78-84.

12. Fogelholm M. Effects of bodyweight reduction on sports performance. Sports Med. 1994;18:249-67.

13. Hiraoka H, Hanaoka Y, Jesmin S, Kimura F, Matsuish Y, Shimizu K, et al. Variation of salivary lgA during weight loss period before a competition among university Judo players. J Clin Med Res. 2019;11:798-806.

14. Shimizu K, Aizawa K, Suzuki N, Masuchi K, Okada H, Akimoto T, et al. Influences of weight loss on monocytes and T-cell subpopulations in male judo athletes. J Strength Cond Res. 2011;25:1943-50

15. Choma CW, Sforzo GA, Keller BA. Impact of rapid weight loss on cognitive function in collegiate wrestlers. Med Sci Sports Exerc. 1998;30:746-9.

16. Reale R, Slater G, Burke LM. Individualised dietary strategies for Olympic combat sports: acute weight loss, recovery and competition nutrition. Eur J Sport Sci. 2017;17:727-40.

17. Romijn JA, Coyle EF, Sidossis LS, Gastaldelli A, Horowitz JF, Endert E, et al. Regulation of endogenous fat and carbohydrate metabolism in relation to exercise intensity and duration. Am J Physiol-Endocrinol Metab. 1993;265:E380-91.

18. Yoon J. Physiological profiles of elite senior wrestlers. Sports Med. 2002;32:225-33

19. Arakawa H, Yamashita D, Arimitsu T, Kawano T, Wada T, Shimizu S. Body composition and physical fitness profiles of elite female Japanese wrestlers aged $<12$ years until $>20$ years. Sports (Basel). 2020;8:81.
20. Fujiyama K, Yamashita D, Nishiguchi S, Ito M. Technical-tactical analysis of men's wrestling: a case study of the 72nd National Athletic Meet of 2017 in Japan. Int J Wresl Sci. 2019;9:1-6.

21. United World Wrestling. World Championships official results Switzerland 2017. https://unitedworldwrestling.org/sites/default/files/2018-03/resul ts_08_paris_2.pdf. Accessed 22 Jun 2020.

22. Rankin JW, Ocel JV, Craft LL. Effect of weight loss and refeeding diet composition on anaerobic performance in wrestlers. Med Sci Sports Exerc. 1996:28:1292-9.

23. Thomas DT, Erdman KA, Burke LM, American College of Sports Medicine Joint Position Statement. Nutrition and athletic performance. Med Sci Sports Exerc. 2016;48:543-68.

24. Kondo E, Shiose K, Yamada Y, Osawa T, Sagayama H, Motonaga K, et al. Effect of thoracic gas volume changes on body composition assessed by air displacement plethysmography after rapid weight loss and regain in elite collegiate wrestlers. Sports. 2019;7:48.

25. Takahashi H, Kamei A, Osawa T, Kawahara T, Takizawa O, Maruyama K. ${ }^{13} \mathrm{C}$ MRS reveals a small diurnal variation in the glycogen content of human thigh muscle. NMR Biomed. 2015;28:650-5.

26. Shiose $K$, Yamada Y, Motonaga K, Sagayama H, Higaki Y, Tanaka H, et al. Segmental extracellular and intracellular water distribution and muscle glycogen after 72-h carbohydrate loading using spectroscopic techniques. J Appl Physiol. 1985;2016(121):205-11.

27. Buehler T, Bally L, Dokumaci AS, Stettler C, Boesch C. Methodological and physiological test-retest reliability of ${ }^{13} \mathrm{C}-\mathrm{MRS}$ glycogen measurements in liver and in skeletal muscle of patients with type 1 diabetes and matched healthy controls. NMR Biomed. 2016;29:796-805.

28. Going SB. Hydrodensitometry and air displacement plethysmography. In: Heymsfield SB, Lohman TG, Wang Z, Going SB,editors, 2nd ed. Human kinetics; 2005. p. 17-33.

29. Hector AJ, Phillips SM. Protein recommendations for weight loss in elite athletes: a focus on body composition and performance. Int J Sport Nutr Exerc Metab. 2018;28:170-7.

30. Kukidome T, Shirai K, Kubo J, Matsushima Y, Yanagisawa O, Homma T, et al MRI evaluation of body composition changes in wrestlers undergoing rapid weight loss. Br J Sports Med. 2008:42:814-8.

31. Nygren AT, Karlsson M, Norman B, Kaijser L. Effect of glycogen loading on skeletal muscle cross-sectional area and T2 relaxation time. Acta Physiol Scand. 2001;173:385-90.

32. Piehl K. Time course for refilling of glycogen stores in human muscle fibres following exercise-induced glycogen depletion. Acta Physiol Scand. 1974:90:297-302.

33. Burke LM, van Loon LJC, Hawley JA. Postexercise muscle glycogen resynthesis in humans. J Appl Physiol. 2017;122:1055-67.

34. Pereira LO, Lancha AH Jr. Effect of insulin and contraction up on glucose transport in skeletal muscle. Prog Biophys Mol Biol. 2004;84:1-27.

35. Blom PC, Hostmark AT, Vaage O, Kardel KR, Maehlum S. Effect of different post-exercise sugar diets on the rate of muscle glycogen synthesis. Med Sci Sports Exerc. 1987;19:491-6.

36. Zachwieja JJ, Costill DL, Pascoe DD, Robergs RA, Fink WJ. Influence of muscle glycogen depletion on the rate of resynthesis. Med Sci Sports Exerc. 1991;23:44-8

37. Ivy JL, Lee MC, Brozinick JT, Reed MJ. Muscle glycogen storage after different amounts of carbohydrate ingestion. J Appl Physiol. 1988;65:2018-23.

38. Burke LM, Hawley JA, Wong SHS, Jeukendrup AE. Carbohydrates for training and competition. J Sports Sci. 2011;29(sup1):S17-27.

39. Burke LM, Collier GR, Hargreaves M. Muscle glycogen storage after prolonged exercise: effect of the glycemic index of carbohydrate feedings. J Appl Physiol. 1993;75:1019-23.

\section{Publisher's Note}

Springer Nature remains neutral with regard to jurisdictional claims in published maps and institutional affiliations. 